\title{
Electronic interaction between single Pt atom and vacancies on boron nitride nanosheets and its influence on the catalytic performance in the direct dehydrogenation of propane
}

\author{
Xiaoying Sun a, Meijun Liu a, Yaoyao Huang a, Bo Li c, Zhen Zhao a,b,* \\ a Institute of Catalysis for Energy and Environment, College of Chemistry and Chemical Engineering, Shenyang Normal University, Shenyang 110034, \\ Liaoning, China \\ b State Key Laboratory of Heavy Oil Processing, China University of Petroleum, Beijing 102249, China \\ ' Institute of Metal Research, Chinese Academy of Sciences, Shenyang 110016, Liaoning, China
}

\section{A R T I C L E I N F}

\section{Article history:}

Received 20 September 2018

Accepted 7 November 2018

Published 5 June 2019

\section{Keywords:}

Propane

Direct dehydrogenation

Platinum

Boron nitride

Single atom catalysis

Density functional theory

Electronic metel-support interaction

\begin{abstract}
A B S T R A C T
The electronic metal-support interaction (EMSI) is one of most intriguing phenomena in heterogeneous catalysis. In this work, this subtle effect is clearly demonstrated by density functional theory (DFT) calculations of single Pt atom supported on vacancies in a boron nitride nanosheet. Moreover, the relation between the EMSI and the performance of Pt in propane direct dehydrogenation (PDH) is investigated in detail. The charge state and partial density of states of single Pt atom show distinct features at different anchoring positions, such as boron and nitrogen vacancies ( $\mathrm{B}_{\mathrm{vac}}$ and $\mathrm{N}_{\mathrm{vac}}$, respectively). Single Pt atom become positively and negatively charged on $\mathrm{B}_{\mathrm{vac}}$ and $\mathrm{N}_{\mathrm{vac}}$, respectively. Therefore, the electronic structure of Pt can be adjusted by rational deposition on the support. Moreover, Pt atoms in different charge states have been shown to have different catalytic abilities in $\mathrm{PDH}$. The DFT calculations reveal that $\mathrm{Pt}$ atoms on $\mathrm{B}_{\mathrm{vac}}\left(\mathrm{Pt}-\mathrm{B}_{\mathrm{vac}}\right.$ ) have much higher reactivity towards reactant/product adsorption and $\mathrm{C}-\mathrm{H}$ bond activation than Pt supported on $\mathrm{N}_{\mathrm{vac}}\left(\mathrm{Pt}-\mathrm{N}_{\mathrm{vac}}\right.$, with larger adsorption energy and lower barrier along the reaction pathway. However, the high reactivity of Pt- $\mathrm{B}_{\mathrm{vac}}$ also hinders propene desorption, which could lead to unwanted deep dehydrogenation. Therefore, the results obtained herein suggest that a balanced reactivity for $\mathrm{C}-\mathrm{H}$ activation in propane and propene desorption is required to achieve optimum yields. Based on this descriptor, a single Pt atom on a nitrogen vacancy is considered an effective catalyst for PDH. Furthermore, the deep dehydrogenation of the formed propene is significantly suppressed, owing to the large barrier on Pt- $\mathrm{N}_{\mathrm{vac}}$. The current work demonstrates that the catalytic properties of supported single Pt atoms can be tuned by rationally depositing them on a boron nitride nanosheet and highlights the great potential of single-atom catalysis in the PDH reaction.
\end{abstract}

(C) 2019, Dalian Institute of Chemical Physics, Chinese Academy of Sciences. Published by Elsevier B.V. All rights reserved.

forming the global energy landscape and has the potential to replace the oil-based energy industry [1,2]. For example, it is estimated that the shale gas reserves of China amount to 134

\footnotetext{
* Corresponding author. E-mail: zhenzhao@cup.edu.cn, zhaozhen@synu.edu.cn

This work was supported by the National Science Foundation of China (91545117), the Natural Science Foundation of Liaoning Province (201602676), the Fundamental Research Funds for Colleges and Universities in Liaoning Province (LQN201703), and the Startup Foundation for Doctors of Shenyang Normal University (BS201620).

DOI: 10.1016/S1872-2067(18)63196-1 | http://www.sciencedirect.com/science/journal/18722067 | Chin. J. Catal., Vol. 40, No. 6, June 2019
} 
trillion cubic meters, and the production of shale gas has reached up to 4.4 billion cubic meters in 2015 [3]. The main component of shale gas is methane, but $\sim 10 \%$ of ethane and propane are also present. Therefore, shale gas is not only a clean energy source but also a chemical feedstock for light alkane molecules. The efficient conversion of light alkane molecules to value-added chemicals has the important role of exploiting the abundant shale gas resources. Due to their price difference, the conversion from ethane or propane to the corresponding alkene is quite profitable. Currently, the propane direct dehydrogenation (PDH) process is one of the efficient industrial routes to produce propylene [4,5]. Platinum and chromium oxides are the conventional catalysts used in the PDH process. However, conventional PDH catalysts face several severe challenges, such as coke formation and catalyst sinister. In particular, coke covers the active sites, leading to reduced activity and loss of stability, which requires the periodic regeneration of the catalyst. The main challenge in the PDH process is that the active sites of the catalyst should be able to activate the stable $\mathrm{C}-\mathrm{H}$ bond in the propane molecule, which has a strong bonding energy of $409 \mathrm{~kJ} / \mathrm{mol}$. On the other hand, the $\mathrm{C}-\mathrm{H}$ bond in the desired propene product, which is much more active than its counterpart in propane, should remain intact for achieving good selectivity under the same conditions. Obviously, it is extremely important to precisely adjust the properties of the active site to achieve this dual task.

Single-atom catalysts (SACs) represent a new catalytic system, which has been applied in various catalytic processes with remarkable performance [6,7]. SACs not only dramatically reduce metal usage, but also possess a unique electronic structure, different from that of bulk or nanosized catalysts. Recently, SACs have exhibited excellent catalytic performance in the activation of light alkanes. In particular, SACs deliver high alkene selectivity and excellent stability. Bao's group [8] used highly dispersed Fe catalysts (0.5\% mass loading) supported on $\mathrm{SiO}_{2}$ for the non-oxidative methane conversion. At $1363 \mathrm{~K}$, the conversion of methane reached $48.4 \%$ and the selectivity of ethene was $48.1 \%$. More impressively, almost no coke was formed during a 60 -h test and the carbon efficiency was nearly $100 \%$. High-resolution transmission electron microscopy (HRTEM) experiments showed that a single Fe atom was embedded into the $\mathrm{SiO}_{2}$ crystalline structure, bonded with two carbon and one silicon atoms. This unique geometry of the active center guarantees that $\mathrm{CH}_{3}$ radicals will be immediately released into the gas phase once they are formed, which prevents the deep reaction. This explains the high selectivity and excellent stability of the catalyst, reflecting the importance of single embedded Fe atoms. Hock's group [9-11] synthesized a series of highly dispersed single metal atom catalysts (Zn, Fe, Co) and applied them in the $\mathrm{PDH}$ reaction. At $550{ }^{\circ} \mathrm{C}$, the selectivity of propylene was above $95 \%$ and the activity remained unchanged during a 24-h test. Near edge X-ray absorption fine structure (NEXAFS) analysis indicated that the first shell of the metal catalyst contained only $\mathrm{M}-\mathrm{O}$ bonds ( $\mathrm{M}=\mathrm{Zn}, \mathrm{Fe}, \mathrm{Co})$ and no $\mathrm{M}-\mathrm{M}$ bond formation was observed. Therefore, the active sites of the catalyst are the single metal atoms. On the other hand, our previous computational work demonstrated that single Pt atoms supported on nitrogen- or boron-doped graphene are potentially useful PDH catalysts [12]. More importantly, the calculations indicated the tunable effects of nitrogen or boron dopants on the graphene support, which can be used to continuously adjust the catalytic performance of the single Pt atoms.

The above experimental and computational investigations show that SACs exhibit remarkable catalytic performance in the activation of $\mathrm{C}-\mathrm{H}$ bonds of light alkanes. However, there is considerable room for further improvements. On the other hand, the origin of the superior catalytic performance of SACs remains elusive to some extent. It has been suggested that the homogeneous and well-defined single centers of SACs might be the origin of their excellent selectivity. However, a SAC is never a true 'single' unit decoupled from the surrounding environment. The interactions between the single atom and the atoms of the support not only stabilize the SAC, but also have significant influence on its catalytic properties. To investigate the subtle interactions between single atom catalysts and support, single Pt atom was anchored on a boron nitride nanosheet, which has been proven to be a good support candidate for single metal atom catalysts in both experimental and theoretical studies [13,14]. Moreover, both boron and nitrogen vacancies ( $\mathrm{B}_{\mathrm{vac}}$ and $\mathrm{N}_{\mathrm{vac}}$, respectively) on boron nitride nanosheets are common observed defects that can serve as stable anchoring sites for the metal catalyst [15-18].

In the current work, first-principles calculations demonstrate that a single Pt atom supported on a boron nitride nanosheet can effectively activate $\mathrm{C}-\mathrm{H}$ bonds in propane and deliver a good selectivity to propene. More importantly, the interactions between reactant (propane) and products (propene and hydrogen) with single Pt atoms are carefully analyzed. The analysis provides a detailed description of the differences in the interactions between $\mathrm{C}-\mathrm{H}$ bonds of propane, propene, and single Pt atoms. Furthermore, a complete reaction pathway is presented, starting from a single Pt atom anchored on both nitrogen and boron vacancies on a boron nitride nanosheet, with emphasis on the competition between propene desorption and deep dehydrogenation. The different electronic interactions between the single Pt atom and nitrogen or boron on the support and the consequent different catalytic performances highlight the importance to take into account the support effects on SACs. In summary, we demonstrate that single Pt atoms on nitrogen vacancies of a boron nitride nanosheet are effective PDH catalysts.

\section{Computational setup}

The calculations reported in this work were performed using periodic, spin-polarized density functional theory (DFT) as implemented in the Vienna ab initio simulation package (VASP) $[19,20]$. The electron-ion interactions were described using the projector augmented wave (PAW) method proposed by Blöchl [21] and implemented by Kresse and Joubert [22]. The PBE functional was used to describe the exchange-correlation effects [23], together with a plane-wave basis set with an energy cutoff of $400 \mathrm{eV}$. Graphene was modeled with a $6 \times 6$ unit cell, 
and a $3 \times 3 \mathrm{k}$-point mesh was used for the Brillouin zone sampling. All atoms in the cell were allowed to relax during the structural optimization, which was stopped when the residual force on the atoms was smaller than $0.05 \mathrm{eV} / \mathrm{A}$. The van der Waals contributions were taken into account using the Grimme scheme [24]. The reaction pathways and barriers were calculated using the climbing image-nudged elastic band (CI-NEB) method [25]. The adsorption energy ( $\left.E_{\text {ads }}\right)$ was calculated as $E_{\text {ads }}=E_{\text {adsorbates } / \text { slab }}-E_{\text {adsorbate }}-E_{\text {slab, }}$ where $E_{\text {adsorbates } / \text { slab }}$ is the total energy of the adsorbates (propane, propene, and $\mathrm{H}_{2}$ ) on Pt- $\mathrm{B}_{\text {vac }}$ or Pt- $\mathrm{N}_{\text {vac }}$ (which denote single Pt atoms on boron and nitrogen vacancies, respectively), Eadsorbate is the energy of the adsorbed molecule in the gas phase, and $E_{\text {slab }}$ is the energy of clean Pt- $\mathrm{B}_{\mathrm{vac}}$ and Pt- $\mathrm{N}_{\mathrm{vac}}$. The reaction barrier was calculated as the energy difference between the initial state and the highest-energy image in the CI-NEB calculations.

\section{Results and discussion}

\subsection{Geometry and electronic structure of single pt atom}

A single Pt atom was anchored on boron and nitrogen vacancies in a boron nitride nanosheet, and the optimized structures are shown in Fig. 1. The Pt atom forms three covalent bonds with three nitrogen atoms around a boron vacancy, as well as three covalent bonds with three boron atoms surrounding a nitrogen vacancy. The bond distances between platinum and the nitrogen or boron atoms of the support are similar (1.96 and $2.02 \AA$, respectively), as shown in Fig. 1 . The Pt charge shows different features on different anchoring positions. The single Pt atom becomes positively and negatively charged at a boron and nitrogen vacancy, with charges of 0.71 and $1.06 e$, respectively. Obviously, the charge transfer shows an opposite trend for single Pt atoms on boron and nitrogen vacancies, which is consistent with our previous results [12]. The decreased or increased Pt charge leads to different electronic structures, as shown by the partial density of states (PDOS) of Pt in Fig. 2. In particular, a Pt- $\mathrm{B}_{\mathrm{vac}}$ atom has a higher number of empty $d$ states just above the Fermi level compared with its Pt- $\mathrm{N}_{\mathrm{vac}}$ counterpart. The PDOS features are consistent with the charge analysis indicating that Pt on a boron vacancy

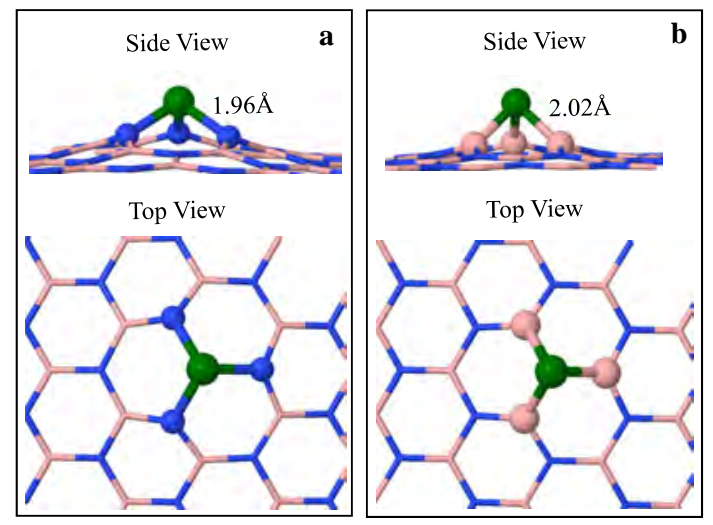

Fig. 1. Optimized structures of single Pt atoms on boron (a) and nitrogen (b) vacancies in a boron nitride nanosheet. Nitrogen, boron, and platinum are colored blue, pink, and green, respectively.
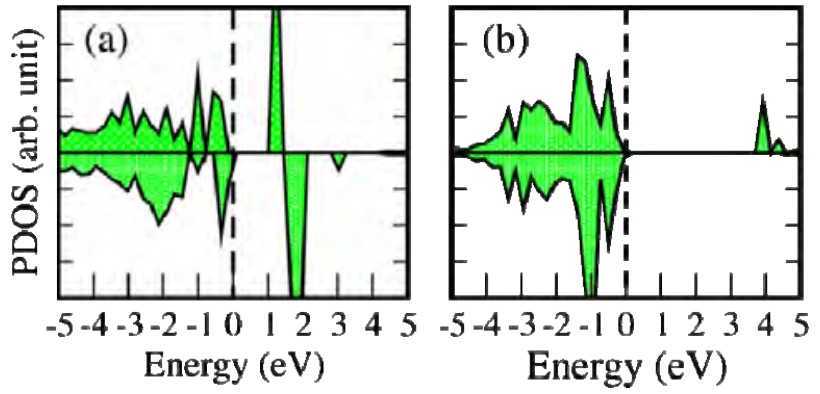

Fig. 2. Partial density of states (PDOS) of single Pt atoms on a boron (a) and nitrogen (b) vacancy. The Fermi level is set to zero.

loses electrons, which leads to empty states just above the Fermi level. The charge and PDOS analyses show that the electronic structure of single Pt atoms has unique features, depending on the anchoring position on the support. Moreover, the above analysis clearly illustrates the electronic interactions between a single Pt atom and either boron or nitrogen vacancies. This effect was reported earlier in the literature, and is complementary to the conventional strong metal-support interaction [26]. Moreover, the different nature of the electronic metal-support interactions significantly influences the catalytic properties of Pt in the PDH process, as will be discussed below.

\subsection{Propane, propene, and hydrogen adsorption}

The interaction between propane, propene, and hydrogen molecules with the active site has an important role in the PDH process. The corresponding adsorption configurations are shown in Fig. 3. The binding energies of propane, propene, and $\mathrm{H}_{2}$ on $\mathrm{Pt}-\mathrm{B}_{\mathrm{vac}}$ and $\mathrm{Pt}-\mathrm{N}_{\mathrm{vac}}$ are $-0.43,-1.70,-0.91$ and -0.12 , $-1.18,-0.13 \mathrm{eV}$, respectively. This clearly shows that the binding energies of the $\mathrm{Pt}-\mathrm{B}_{\mathrm{vac}}$ center are larger than those of the Pt- $\mathrm{N}_{\text {vac }}$ one, for all tested molecules. It has been suggested that Pt with empty $d$ orbitals has a better reactivity towards binding small molecules. Therefore, it is expected that $\mathrm{Pt}-\mathrm{B}_{\mathrm{vac}}$ can bind molecules more strongly than $\mathrm{Pt}-\mathrm{N}_{\mathrm{vac}}$, which is consistent with

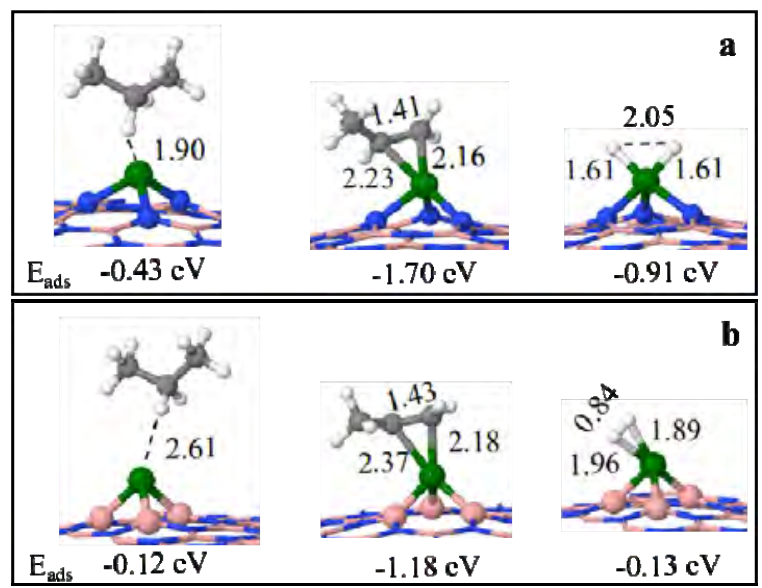

Fig. 3. Adsorption energy ( $\left.E_{\text {ads }}\right)$ and structure of propane, propene, and hydrogen molecules on (a) Pt- $\mathrm{B}_{\mathrm{vac}}$ and (b) Pt- $\mathrm{N}_{\mathrm{vac}}$. The bond distances (in $\AA$ ) are also indicated. Nitrogen, boron, platinum, carbon, and hydrogen are colored blue, pink, green, gray, and white, respectively. 


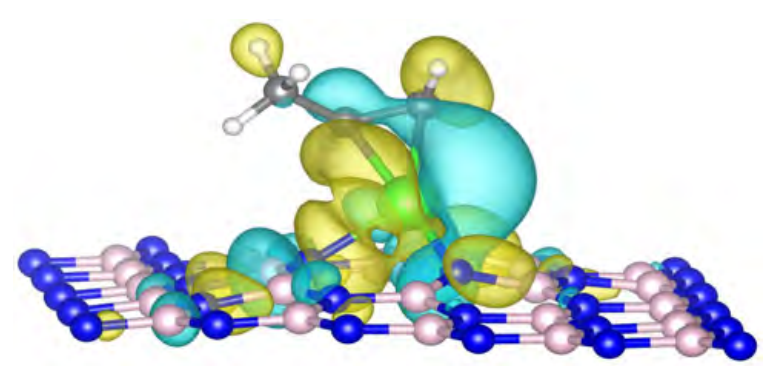

Fig. 4. Bonding orbital formed between adsorbed propene and a sup-

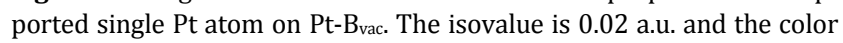
scheme is the same as in Fig. 3.

the calculated adsorption energies. It was also found that the binding energy of propane is much lower than that of propene,

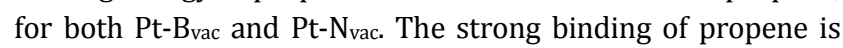
detrimental to the selectivity of the PDH process, as the formed propene is difficult to desorb. In propane adsorption, one of the secondary hydrogen atoms points towards the single Pt atom on boron nitride, and the distances between hydrogen and Pt- $\mathrm{B}_{\text {vac }}$ and Pt- $\mathrm{N}_{\text {vac }}$ species are 1.90 and $2.61 \AA$, respectively. Based on the binding energy and the distance from $\mathrm{Pt}$, propane adsorption can be considered as a weak physisorption. The binding energy and configuration of propane adsorption via primary hydrogen were also examined, and are shown in Fig. S1 (Supporting Information). In contrast, the interaction between propene and Pt can be considered as a strong covalent bond, which involves a much higher binding energy than propane, as shown in Fig. 4. Moreover, propene is adsorbed in a different configuration compared with propane. The $\mathrm{C}=\mathrm{C}$ bond of the propene molecule directly interacts with Pt via $\pi$ adsorption, and the distances of the two carbon atoms from Pt at the boron vacancy site are 2.16 and $2.23 \AA$, as shown in Figs. 3 and 4. It should be noted that propene prefers a di- $\sigma$ adsorption on $\mathrm{Pt}(111)$ [27]. The missing neighboring Pt atom prevents propene from assuming a di- $\sigma$ adsorption configuration. The above analysis clearly indicates that propene has much higher reactivity than propane. Therefore, the best strategy to obtain a reasonable yield in the PDH process is to maximize the ability of the active site to break the $\mathrm{C}-\mathrm{H}$ bonds of propane while weakening the binding of propene. Another product of the PDH process is hydrogen. Hydrogen is often mixed with propane in the PDH input stream, for various purposes such as selectivity increase or coke reduction. However, the exact role played by hydrogen is still debated. The binding energies of the hydrogen molecule on Pt- $\mathrm{B}_{\mathrm{vac}}$ and Pt- $\mathrm{N}_{\mathrm{vac}}$ are -0.91 and $-0.13 \mathrm{eV}$, respectively. The bond distance of the adsorbed hydrogen increases to $2.05 \AA$ on Pt- $\mathrm{B}_{\mathrm{vac}}$, as shown in Fig. 3. Overall, the calculations indicate that a supported single Pt atom on a boron vacancy has higher reactivity towards reactant/product adsorption than its counterpart on a nitrogen vacancy.

\subsection{Reaction pathway to propene formation}

To further understand the mechanism of $\mathrm{C}-\mathrm{H}$ bond activation of propane, the complete $\mathrm{PDH}$ reaction pathway was investigated and shown in Fig. 5 and Fig. S2. The first $\mathrm{C}-\mathrm{H}$ bond activation in propane is often deemed as the step with the largest barrier in the PDH process. There are two different hydrogen atoms in propane, denoted as primary and secondary hydrogen, respectively. The calculated barriers for the first abstraction of secondary and primary hydrogens on Pt- $\mathrm{B}_{\mathrm{vac}}$ are 0.64 and $0.74 \mathrm{eV}$, respectively, whereas the corresponding values for Pt-N $\mathrm{N}_{\mathrm{vac}}$ are 0.82 and $1.05 \mathrm{eV}$, respectively, as shown in Fig. 5 and Fig. S2 (primary hydrogen). The calculated barriers clearly indicate that the abstraction of the secondary hydrogen is more favorable than that of the primary hydrogen. Therefore, the reaction is expected to begin with the secondary hydrogen abstraction. Furthermore, Pt- $\mathrm{B}_{\mathrm{vac}}$ shows higher reactivity towards $\mathrm{C}-\mathrm{H}$ bond activation than $\mathrm{Pt}-\mathrm{N}_{\mathrm{vac}}$, based on the corresponding transition state (TS1) barriers. In the secondary hydrogen abstraction on $\mathrm{Pt}-\mathrm{B}_{\mathrm{vac}}$, the $\mathrm{C}-\mathrm{H}$ bond is stretched to a distance of $1.60 \AA$ in the transition state, as shown in Fig. 5(a). Compared with the propane physisorption state (INI), the secondary carbon atom moves closer to $\mathrm{Pt}$ at the transition state, causing the breaking of the $\mathrm{C}-\mathrm{H}$ bond. A similar process is also found on Pt- $\mathrm{N}_{\mathrm{vac}}$ as shown in Fig. 5(b). Moreover, the bond distances between the secondary carbon and Pt are 2.24 and $2.55 \AA$, respectively, for Pt- $\mathrm{B}_{\text {vac }}$ and Pt- $\mathrm{N}_{\text {vac; }}$ the longer distance could also contribute to the higher barrier on the latter site. After the first $\mathrm{C}-\mathrm{H}$ bond breaking in propane, both dissociated fragments $\left(\mathrm{H}\right.$ and $\left.\mathrm{C}_{3} \mathrm{H}_{7}\right)$ bind with $\mathrm{Pt}$, forming the intermediate labeled IM1 in Fig. 5. Instead of the dissociative adsorption of propane, the release of the $\mathrm{C}_{3} \mathrm{H}_{7}$ radical formed from the first $\mathrm{C}-\mathrm{H}$ bond breaking into the gas phase is another possible pathway. As shown in Fig. S3, the barriers of the radical path-

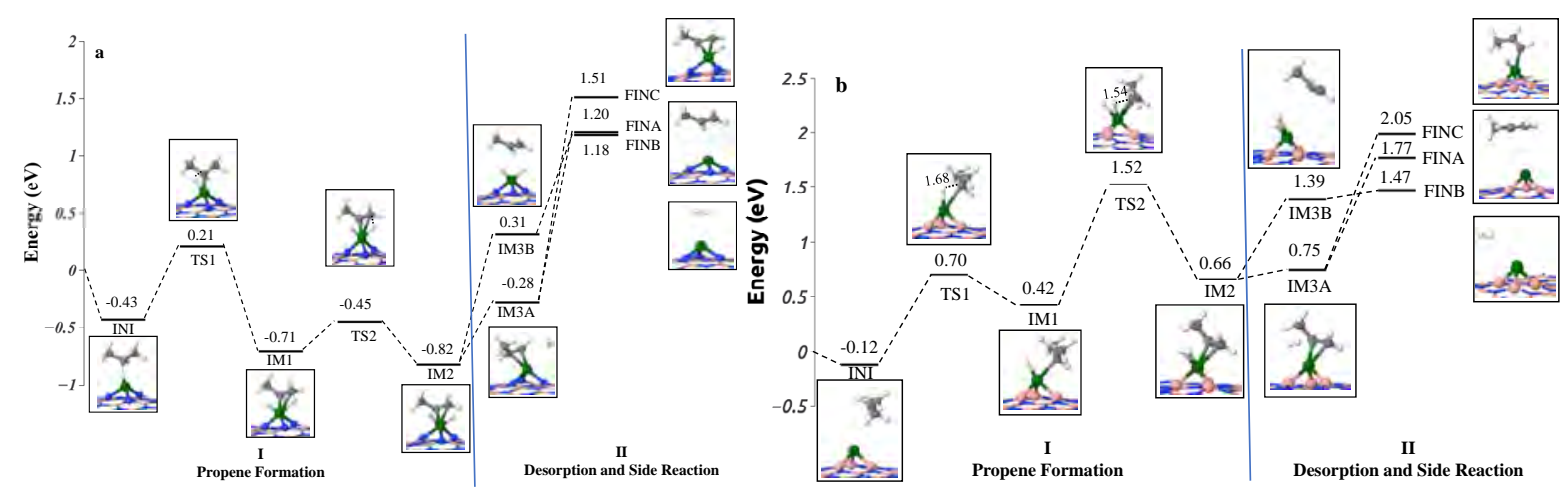

Fig. 5. Reaction pathway for PDH on supported single Pt on a boron (a) or nitrogen (b) vacancy. The reaction pathway is divided in two processes: (I) propene formation and (II) production, desorption, and side reaction (deep dehydrogenation). The color scheme is same as in Fig. 3. 
way on Pt- $\mathrm{B}_{\text {vac }}$ and Pt- $\mathrm{N}_{\text {vac }}$ were calculated to be 1.44 and 0.91 $\mathrm{eV}$, respectively. It can thus be concluded that dissociative adsorption is preferred over radical generation for the first $\mathrm{C}-\mathrm{H}$ bond activation of propane. Further hydrogen abstraction involves the primary hydrogen from the adsorbed $\mathrm{C}_{3} \mathrm{H}_{7}$, as shown in Fig. 5. The calculated barriers for the second hydrogen abstraction on Pt-B $\mathrm{B}_{\mathrm{vac}}$ and Pt- $\mathrm{N}_{\mathrm{vac}}$ (TS2) are 0.26 and $1.10 \mathrm{eV}$, respectively. Again, Pt- $\mathrm{B}_{\mathrm{vac}}$ shows higher reactivity than $\mathrm{Pt}-\mathrm{N}_{\mathrm{vac}}$. On the other hand, the barrier of the second hydrogen abstraction is larger than that of the first one. After the second hydrogen abstraction, the desired propene product is formed. As shown in the IM2 structure in the reaction pathway for propene formation in Fig. 5, both propene and hydrogen atoms are adsorbed on Pt. The desorption of propene and hydrogen atoms will then lead to the formation of the PDH products and to the recovery of the active sites, completing the catalytic cycle.

\subsection{Desorption and side reactions}

The regeneration of active sites and desorption of propene are not very straightforward processes. As shown in Fig. 3, propene is strongly bound to the Pt atom; therefore, it is expected that its desorption will require a large amount of energy [28]. In a previous study, Hauser et al. [29] used DFT calculations to demonstrate that the desorption of propene from a supported $\mathrm{Pt}_{4}$ cluster is the step with the highest energy barrier $(1.38 \mathrm{eV})$ in the PDH process. A further complication is that not only propene but also hydrogen atoms should be released from the active sites. This is in contrast with the regeneration of active sites on vanadium oxide, whose two hydroxyls are easily converted into a water molecule, in an almost barrierless process [30].

The desorption of propene and hydrogen atoms were carefully investigated in the current work and are illustrated in the second part of Fig. 5. There are two possible routes for the desorption of the products, in which either propene or hydrogen are desorbed from the catalyst first. The calculations indicate that the desorption of hydrogen atoms as a hydrogen molecule is more favorable than that of propene, with barriers of 0.54 and $0.09 \mathrm{eV}$ on Pt- $\mathrm{B}_{\mathrm{vac}}$ and $\mathrm{Pt}-\mathrm{N}_{\mathrm{vac}}$, respectively (IM3A). The barriers for propene desorption from Pt- $\mathrm{B}_{\mathrm{vac}}$ and $\mathrm{Pt}-\mathrm{N}_{\mathrm{vac}}$ were calculated to be 1.13 and $0.73 \mathrm{eV}$, respectively, which are significantly larger than those of hydrogen desorption (IM3B). Therefore, it is reasonable to conclude that the hydrogen molecule is desorbed from single Pt before propene. In the next step, the barriers for propene desorption from Pt- $\mathrm{B}_{\mathrm{vac}}$ and Pt- $\mathrm{N}_{\text {vac }}$ were calculated to be 1.48 and $1.02 \mathrm{eV}$, respectively (FINA). It should be noted that the calculated barriers for propene desorption are much larger than those obtained for hydrogen desorption. This can be attributed to the much weaker interactions between hydrogen and the catalyst compared with the propene-catalyst interactions. Moreover, the calculated barriers for product desorption are higher or close to the ones calculated for the pathway from propane to propene on Pt-Nvac and $\mathrm{Pt}-\mathrm{B}_{\mathrm{vac}}$. This is a further indication that the product desorption and active site regeneration might be the rate-limiting step.
One of the important properties of PDH catalysts is that they limit the deep dehydrogenation of propene that could lead to coke formation and cover the active sites. The calculated barriers for hydrogen abstraction from adsorbed propene (1.79 and $1.30 \mathrm{eV}$ on $\mathrm{Pt}-\mathrm{B}_{\mathrm{vac}}$ and $\mathrm{Pt}-\mathrm{N}_{\mathrm{vac}}$, respectively) are larger than those for propene desorption. Therefore, the single Pt atom supported on boron nitride has an excellent selectivity.

\subsection{Discussion}

In the current work, the nature of the electronic perturbation on single Pt atoms induced by different anchoring sites was clearly elucidated based on charge and PDOS analyses. This electronic perturbation leads to $\mathrm{Pt}-\mathrm{B}_{\mathrm{vac}}$ having higher reactivity towards propane/propene adsorption and $\mathrm{C}-\mathrm{H}$ activation than Pt- $\mathrm{N}_{\mathrm{vac}}$, as shown by larger adsorption energy and smaller barrier values. On the other hand, the desorption of products such as propene and hydrogen from $\mathrm{Pt}-\mathrm{B}_{\mathrm{vac}}$ is more difficult than from Pt- $\mathrm{N}_{\text {vac. }}$ This observation is consistent with the higher reactivity of Pt- $\mathrm{B}_{\mathrm{vac}}$, which leads to strong interactions with propene and hydrogen. The calculations clearly highlight the challenge faced by active centers in PDH. For propene formation, they should possess a reactivity sufficient to break the strong $\mathrm{C}-\mathrm{H}$ bonds of propane; however, their reactivity should not be too active to hinder propene desorption and lead to deep dehydrogenation. Therefore, a balanced reactivity towards the $\mathrm{C}-\mathrm{H}$ bonds of propane/propene is the key to obtain reasonable yields in the PDH process. The current work suggests that a single Pt atom supported on a nitrogen vacancy site on boron nitride has a balanced reactivity for $\mathrm{C}-\mathrm{H}$ bond activation and propene desorption, as the two processes exhibit similar barriers. Propene could be released under the conditions favorable for $\mathrm{C}-\mathrm{H}$ bond activation, thus hindering side reactions and deep dehydrogenation. Therefore, reasonable propene selectivity and propane conversion are simultaneously obtained. In addition, the present results clearly demonstrate the tunable effect of different anchoring positions on the support of the single Pt atom.

\section{Conclusions}

First-principles calculations were performed to study the direct dehydrogenation of propane on single Pt atoms supported on boron and nitrogen vacancies in a boron nitride nanosheet. Boron and nitrogen atoms surrounding the vacancies lead to charge transfers of opposite sign to the supported single Pt atom, and therefore significantly alter the electronic structure of Pt. The calculations indicate that Pt supported on a boron vacancy has a higher reactivity towards propane, propene, and hydrogen adsorption compared with Pt on a nitrogen vacancy. Furthermore, the calculations reveal that dissociative adsorption is preferred over radical formation for the first $\mathrm{C}-\mathrm{H}$ bond activation in propane. Moreover, Pt supported on a boron vacancy exhibits a much smaller barrier along the reaction pathway leading from propane to propene, compared with its Pt- $\mathrm{N}_{\text {vac }}$ counterpart. On the other hand, the most critical step in the PDH process turns out to be the desorption of propene and 


\section{Graphical Abstract}

Chin. J. Catal., 2019, 40: 819-825 doi: 10.1016/S1872-2067(18)63196-1

Electronic interaction between single Pt atom and vacancies on boron nitride nanosheets and its influence on the catalytic performance in the direct dehydrogenation of propane

XiaoYing Sun, MeiJun Liu, YaoYao Huang, Bo Li, Zhen Zhao*

Shenyang Normal University; China University of Petroleum; Institute of Metal Research, Chinese Academy of Sciences

\section{A balanced reactivity for \\ C-H activation and propene desorption}
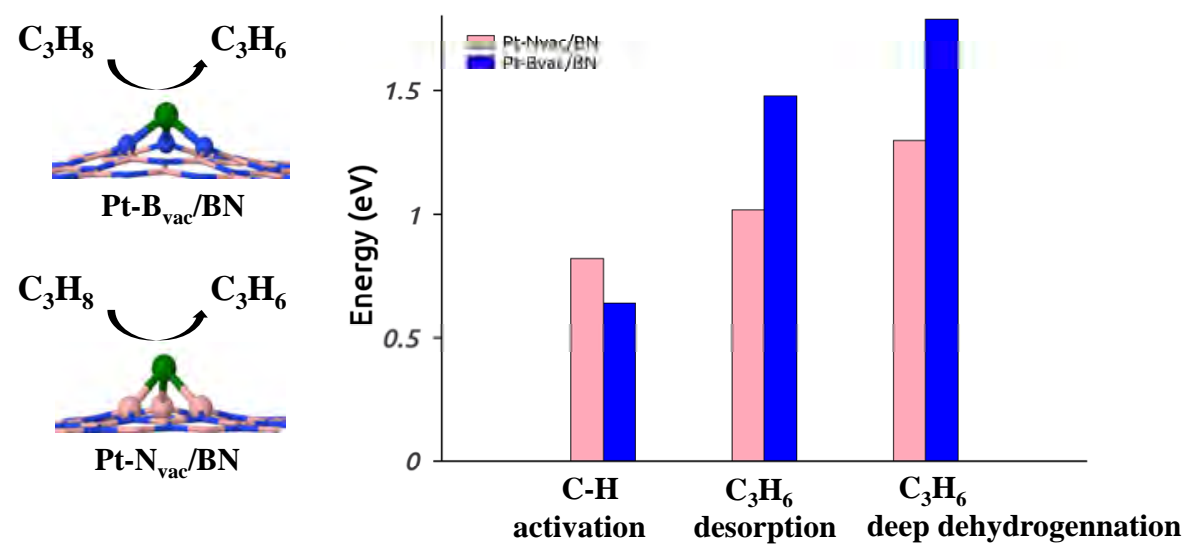

The electronic interactions between support and metal have opposite effects on the catalytic properties of single Pt atom supported on boron and nitrogen vacancies. A balanced reactivity ( $\mathrm{C}-\mathrm{H}$ bond activation and $\mathrm{C}_{3} \mathrm{H}_{6}$ desorption) descriptor is proposed for controlling the propane dehydrogenation process.

hydrogen from the catalysts. The calculations indicate that the desorption of hydrogen precedes that of propene, owing to a much smaller barrier. Furthermore, Pt- $\mathrm{N}_{\mathrm{vac}}$ exhibits a better product desorption performance than $\mathrm{Pt}-\mathrm{B}_{\mathrm{vac}}$. A larger barrier is found for deep dehydrogenation of propene on a supported Pt catalyst compared with that for propene desorption, which guarantees a good selectivity. Overall, the present results suggest that a single supported Pt on a nitrogen vacancy is an effective PDH catalyst with a balanced ability to activate $\mathrm{C}-\mathrm{H}$ bonds in propane and enable product desorption.

\section{References}

[1] J. Baltrusaitis, I. Jansen, J. D. Schuttlefield Christus, Catal. Sci. Technol., 2014, 4, 2397-2411.

[2] J. N. Armor, Catal. Today, 2014, 236, 171-181.

[3] C. Zou, D. Dong, S. Wang, J. Li, X. Li, Y. Wang, D. Li, K. Cheng, Petroleum Exploration and Development, 2010, 37, 641-653.

[4] J. J. H. B. Sattler, J. Ruiz-Martinez, E. Santillan-Jimenez, B. M. Weckhuysen, Chem. Rev., 2014, 114, 10613-10653.

[5] C. A. Carrero, R. Schloegl, I. E. Wachs, R. Schomaecker, ACS Catal., 2014, 4, 3357-3380.

[6] X. F. Yang, A. Wang, B. Qiao, J. Li, J. Liu, T. Zhang, Acc. Chem. Res., 2013, 46, 1740-1748.

[7] S. Liang, C. Hao, Y. Shi, ChemCatChem, 2015, 7, 2559-2567.

[8] X. Guo, G. Fang, G. Li, H. Ma, H. Fan, L. Yu, C. Ma, X. Wu, D. Deng, M.
Wei, D. Tan, R. Si, S. Zhang, J. Li, L. Sun, Z. Tang, X. Pan, X. Bao, Science, 2014, 344, 616-619.

[9] B. Hu, A. B. Getsoian, N. M. Schweitzer, U. Das, H. Kim, J. Niklas, O. Poluektov, L. A. Curtiss, P. C. Stair, J. T. Miller, A. S. Hock, J. Catal., 2015, 322, 24-37.

[10] B. Hu, N. M. Schweitzer, G. Zhang, S. J. Kraft, D. J. Childers, M. P. Lanci, J. T. Miller, A. S. Hock, ACS Catal., 2015, 5, 3494-3503.

[11] N. M. Schweitzer, B. Hu, U. Das, H. Kim, J. Greeley, L. A. Curtiss, P. C. Stair, J. T. Miller, A. S. Hock, ACS Catal., 2014, 4, 1091-1098.

[12] X. Sun, P. Han, B. Li, Z. Zhao, J. Phys. Chem. C, 2018, 122, 1570-1576.

[13] X. Liu, T. Duan, C. Meng, Y. Han, RSC Adv., 2015, 5, 10452-10459.

[14] W. Zhu, Z. Wu, G. S. Foo, X. Gao, M. Zhou, B. Liu, G. M. Veith, P. Wu, K. L. Browning, H. N. Lee, H. Li, S. Dai, H. Zhu, Nat. Commun., 2017, 8, 15291 .

[15] S. Lin, J. Huang, X. Ye, Appl. Surf. Sci., 2014, 320, 237-243.

[16] S. Lin, X. Ye, J. Huang, Phys. Chem. Chem. Phys., 2015, 17, 888-895.

[17] C. Huang, X. Ye, C. Chen, S. Lin, D. Xie, Comput. Theor. Chem., 2013, $1011,5-10$.

[18] S. Lin, X. Ye, R. S. Johnson, H. Guo, J. Phys. Chem. C, 2013, 117, 17319-17326.

[19] G. Kresse, J. Furthmuller, Phys. Rev. B, 1996, 54, 11169-11186.

[20] G. Kresse, J. Furthmuller, Comp. Mater. Sci., 1996, 6, 15-50.

[21] P. E. Blochl, Phys. Rev. B, 1994, 50, 17953-17979.

[22] G. Kresse, D. Joubert, Phys. Rev. B, 1999, 59, 1758-1775.

[23] J. P. Perdew, K. Burke, M. Ernzerhof, Phys. Rev. Lett., 1996, 77, 3865-3868.

[24] S. Grimme, J. Comput. Chem. 2006, 27, 1787-1799. 
[25] G. Henkelman, B. P. Uberuaga, H. Jonsson, J. Chem. Phys., 2000, 113, 9901-9904.

[26] C. T. Campbell, Nat. Chem., 2012, 4, 597-598.

[27] L. Nykänen, K. Honkala, J. Phys. Chem. C, 2011, 115, 9578-9586.

[28] M. L. Yang, Y. A. Zhu, C. Fan, Z. J. Sui, D. Chen, X. G. Zhou, Phys.
Chem. Chem. Phys., 2011, 13, 3257-3267.

[29] A. W. Hauser, J. Gomes, M. Bajdich, M. Head-Gordon, A. T. Bell, Phys. Chem. Chem. Phys., 2013, 15, 20727-20734.

[30] H. Fu, Z. P. Liu, Z. H. Li, W. N. Wang, K. N. Fan, J. Am.Chem. Soc., 2006, 128, 11114-11123.

\title{
单原子铂和氮化嗍载体之间电子作用及其对丙烷脱氢反应催化性能的影响
}

\author{
孙晓颖 ${ }^{\mathrm{a}}$, 刘美君 ${ }^{\mathrm{a}}$, 黄瑶瑶, 李 波, 赵 震, ${ }^{\mathrm{a}, \mathrm{b}, *}$ \\ a 沈阳师范大学化学化工学院能源与环境催化研究所, 辽宁沈阳 110034 \\ b 中国石油大学(北京)重质油国家实验室, 北京102249 \\ c中国科学院金属研究所, 辽宁沈阳 110016
}

\begin{abstract}
摘要: 随着世界范围内大规模页岩气资源的发现和开采, 如何进一步高效转化页岩气生成高附加值化学品是提升页岩气 资源利用率和增加经济收益的关键. 页岩气主要的组分是甲烷, 同时还包含 $10 \%$ 左右的乙烷和丙烷. 另一方面, 由于当前 丙烯的市场价格远远超过丙烷, 因此丙烷到丙烯的催化转化是高效利用我国页岩气资源的有效途径. 丙烷直接脱氢制丙 烯是工业上常见的催化转化丙烷的方法. 丙烷直接脱氢面临的主要问题是反应中积碳覆盖活性位导致催化剂失活. 最近, 单原子催化剂在烷烃碳氢键活化过程中表现出优异的催化性能, 尤其在抑制深度反应、减少积碳方面有突出效果. 然而, 单原子催化剂在苛刻反应条件下容易团聚失活, 因此选择合适的载体材料是单原子催化剂设计的关键.

本文利用氮化嗍作为单原子铂催化剂载体, 考察了其在丙烷直接脱氢反应中的催化性能. 第一性原理计算表明, 氮化 硼载体上硼和氮空穴是单原子铂稳定的针定点, 同时单原子铂在硼和氮空穴上表现出截然相反的电子结构. 电荷分析表 明, 在嗍和氮空穴位上的单原子铂分别失去 $0.71 e$ 和得到 $1.06 e$ 个电荷. PDOS分析表明, 在硼空穴上单原子铂在费米能级之 上有更多的空轨道, 有利于得到电子. 通过密度泛函理论计算构建了从丙烷到丙烯的完整反应路径. 计算结果表明, 负载 在硼空穴上的单原子铂比在氮空穴上的具有更好的碳氢键活化能力. 在硼空穴和氮空穴上第一个碳氢键断裂能垒分别是 0.64 和 0.82 电子伏特, 第二个碳氢键断裂能垒分别是 0.26 和 1.10 电子伏特. 计算还详细分析了产物脱附过程, 结果表明氢气 先于丙烯脱附的路径能垒更小. 同时丙烯脱附能垒已经接近或者超过丙烷碳氢键活化能垒. 因此, 对于丙烷直接脱氢反 应, 催化剂要兼顾丙烷碳氢键活化和产物脱附两个方面. 虽然负载在硼空穴上的单原子铂催化剂有着优异的丙烷碳氢键 活化能力, 但产物丙烯由于强相互作用而难以脱附. 另一方面, 负载在氮空穴上的单原子铂对于碳氢键活化和产物脱附具 有比较均衡的反应活性.

综上所述, 氮化嗍载体和单原子铂催化剂之间的电子结构作用对丙烷直接脱氢反应的催化性能有着重要影响. 负载 在嗍和氮空穴的单原子铂表现出截然相反的电子结构, 电子结构差异导致不同的催化性能. 基于计算结果, 负载在氮空穴 上的铂单原子具有优异的丙烷直接脱氢催化性能. 本工作为进一步加深理解单原子催化中载体的作用提供了理论依据.
\end{abstract}

关键词: 丙烷; 直接脱氢; 铂; 氮化硼; 单原子催化; 密度泛函理论; 金属-载体相互作用

收稿日期: 2018-09-20. 接受日期: 2018-11-07. 出版日期: 2019-06-05.

*通讯联系人. 电话: (024)86579800; 传真: (024)86574216; 电子信箱: zhenzhao@cup.edu.cn, zhaozhen@synu.edu.cn 基金来源：国家自然科学基金(91545117); 辽宁省自然科学基金(201602676); 辽宁省高等学校基本科研项目(LQN201703); 沈阳 师范大学博士启动基金(BS201620).

本文的电子版全文由Elsevier出版社在ScienceDirect上出版(http://www.sciencedirect.com/science/journal/18722067). 